\title{
High Performance Mixed-Matrix Electrospun Membranes for Ammonium Removal from Wastewaters
}

\author{
Shu-Ting Chen ${ }^{1}$, Sumith Ranil Wickramasinghe ${ }^{1}$ and Xianghong Qian ${ }^{2, *}$ \\ 1 Department of Chemical Engineering, University of Arkansas, Fayetteville, AR 72701, USA; \\ sc068@uark.edu (S.-T.C.); swickram@uark.edu (S.R.W.) \\ 2 Department of Biomedical Engineering, University of Arkansas, Fayetteville, AR 72701, USA \\ * Correspondence: xqian@uark.edu; Tel.: +1-479-575-8401
}

Citation: Chen, S.-T.;

Wickramasinghe, S.R.; Qian, X. High

Performance Mixed-Matrix

Electrospun Membranes for Ammonium Removal from

Wastewaters. Membranes 2021, 11, 440

https://doi.org/10.3390/

membranes 11060440

Academic Editor: Claudia Ursino

Received: 1 April 2021

Accepted: 1 June 2021

Published: 11 June 2021

Publisher's Note: MDPI stays neutral with regard to jurisdictional claims in published maps and institutional affiliations.

\begin{abstract}
Mixed-matrix electrospun membranes were developed to investigate ammonium removal from low ammonium concentration wastewaters for the first time. Particles derived from the inexpensive zeolite 13X were successfully incorporated into polyethersulfone (PES) matrices. The fabricated mixed-matrix electrospun membranes demonstrate high ammonium removal capacity reaching over $55 \mathrm{mg} / \mathrm{g}_{\text {zeolite, }}$ more than 2.5 times higher than the previously fabricated mixed-matrix membranes via non-solvent induced phase inversion. Moreover, the membranes fabricated exhibit high permeability and ease of regeneration. Over $90 \%$ of total ammonium nitrogen (TAN) can be removed from low TAN wastewaters such as aquaculture wastewaters. In addition to zeolite 13X, other zeolite particles including zeolite $\mathrm{Y}$, zeolite 3A and 4A were also incorporated into the membrane matrix. The inexpensive zeolite $13 \mathrm{X}$ show the highest ammonium exchange capacity. Particle type, loading and the level of its dispersion all affect TAN removal capacity.
\end{abstract}

Keywords: ammonium removal; wastewater; mixed-matrix membranes; zeolite; electrospinning

\section{Introduction}

The biological production of ammonia $\left(\mathrm{NH}_{3}\right)$ is part of the natural metabolic process across all fauna, from humans to fish. Ammonia is a major protein metabolite released to the environment. It is also an essential nutrient for plants and a key component of the nitrogen cycle. Depending on the acidity or $\mathrm{pH}$ of the aquatic system, the equilibrium between the molecular form $\left(\mathrm{NH}_{3}\right)$ or protonated form $\left(\mathrm{NH}_{4}{ }^{+}\right)$can shift dramatically with one or the other being the dominant species. Environmental protection agency (EPA) regulates the discharging limit of total ammonia nitrogen (TAN) including both $\mathrm{NH}_{4}{ }^{+}$and $\mathrm{NH}_{3}$ from the wastewater treatment plants. Municipal wastewater treatment typically employs aerobic process to convert TAN to nitrite $\left(\mathrm{NO}_{2}{ }^{-}\right)$and further to nitrate $\left(\mathrm{NO}_{3}{ }^{-}\right)$. Nitrate is ultimately converted to $\mathrm{N}_{2}$ and released to air via the anaerobic process. The biological conversion process is generally effective once established but slow. However, it does take a long time to establish the bacterial culture during the initial start-up phase. In addition, it may be ineffective when there is a sudden surge of TAN in the wastewater as biological conversion is slow.

Ammonia is released to the aquaculture water during protein metabolism by fish and via bacterial digestion of organic matter. Ammonia is rather toxic to fish and has to be maintained below $0.05 \mathrm{mg} / \mathrm{L}$ (ppm). This puts the maximum TAN in aquaculture water to be $\sim 1.5 \mathrm{ppm}$ at neutral $\mathrm{pH}$. In order to maintain this level of TAN, the aquaculture water has to be often partially replaced with fresh water. Zeolite materials have been employed for the removal of ammonium ion from wastewaters [1-6]. Previous studies indicate that the inexpensive natural zeolite 13X can perform ion exchange with ammonium ion with high capacity [6]. However, zeolite $13 \mathrm{X}$ is not stable in water and cannot be applied effectively as an ammonium absorbent. Our previous work [7] has shown that a mixedmatrix membrane incorporating cheap natural zeolite $13 \mathrm{X}$ particles can effectively remove 
$\mathrm{NH}_{4}{ }^{+}$from aquaculture wastewater via ion-exchange to reach TAN concentration below $1 \mathrm{ppm}$. No leach of zeolite materials has been observed. Three different methods were used to fabricate the mixed-matrix membranes and fibers. One involves non-solvent induced phase inversion by mixing the zeolite particles with the polysulfone (PSU) in 1-methyl-2-pyrrolidinone (NMP). The maximum amount of zeolite incorporated without compromising the mechanical property of the membrane is 50\% of the PSU amount. Our results indicate that the higher the amount of zeolite particles incorporated, the higher the capacity of the mixed-matrix membrane for removing ammonium ion via ion-exchange. The maximum capacity reached is $19.8 \mathrm{mg}$ of TAN per $\mathrm{g}$ of zeolite $\left(\mathrm{mg} / \mathrm{g}_{\text {zeolite }}\right)$ for the membrane with $15 \%$ PSU and zeolite loading of $50 \%$ PSU. The second approach is the formation of zeolite-containing fibers by mixing the zeolite with PSU in NMP similar to the preparation of mixed-matrix membrane. The prepared solution was then dispensed into water via a syringe. These fibers exhibit a maximum ammonium exchange capacity of $5.4 \mathrm{mg} / \mathrm{g}_{\text {zeolite }}$ at $15 \%$ PSU and zeolite loading of $50 \%$ PSU. The third approach involves the pore-filling of zeolite through the supporting structure from the back of an existing $30 \mathrm{kD}$ polyethersulfone (PES) membrane. The maximum capacity reached is $10.4 \mathrm{mg} / \mathrm{g}_{\text {zeolite. }}$ In all these approaches, it seems that the capacity is limited by the zeolite loading.

In order to incorporate more zeolite particles into the membrane matrix, electrospinning technique has been used here to fabricate mixed-matrix membranes. Fabrication of electrospun membranes involve the application of a high voltage to produce nanofibers from a charged polymer solution or melt. The surface topology, fiber morphology, and orientation of electrospun membranes depend strongly on the nature of the casting solution and the operating condition. The rheology of the polymer solution is most critical to the structure and properties of the spun nanofiber. Electrospun fibers are also affected by the voltage applied, solution flow rate, and tip-collector distance, as well as chamber temperature and humidity. Careful control of the operating condition and casting solution could lead to the production of smooth, defect-free, highly porous non-woven nanofiber membranes. In contrast to phase inversion method, the electrospun membranes have relative uniform pore sizes with high pore interconnectivity and high porosity $(\sim 80 \%)[8,9]$. In addition, electrospun membranes have robust mechanical properties and the possibility to incorporate different additives, such as zeolite particles. These properties lead to the wide industrial application of electrospinning for membrane fabrications [10,11]. Besides membranes used for separation, electrospun materials have significant potential for applications in bioengineering, catalysis, and many other areas [12-16]. Electrospun membranes have been extensively studied for biomedical applications due to their biocompatibility and biodegradability [17]. Previously we fabricated weak anion exchange electrospun membranes for protein purifications [18]. Here mixed-matrix electrospun membranes are synthesized for ammonium removal from wastewaters containing both low and high TAN concentration levels.

\section{Materials and Methods}

\subsection{Materials}

Polyethersulfone (PES; MW 60,000) in powder form as membrane material was purchased from BASF (Ludwigshafen, Germany). N, N-dimethylformamide (DMF) ( $\geq 99.8 \%$ ACS), sodium hypochlorite (12.5\% in aqueous solution) and sodium chloride ( $\mathrm{NaCl}$ ) (ACS grade) were purchased from VWR (Radnor, PA, USA). Ammonium chloride ( $\geq 99 \%)$ was purchased from Alfa Aesar (Haverhill, MA, USA). Liquid phenol ( $>89 \%)$ was purchased from Sigma-Aldrich (St. Louis, MO, USA). Sodium nitroprusside dihydrate $(\geq 98 \%)$ was purchased from MP biomedicals (FKA ICN BIOMED) (Santa Ana, CA, USA). Sodium hydroxide ( $\geq 98 \%$, ACS grade) was purchased from Amresco (Solon, OH, USA). Sodium citrate dehydrate ( $\geq 99 \%)$ was purchased from J.T. Baker (Phillipsburg, NJ, USA). All chemicals were used without further purifications. Zeolite 13X molecular sieve (Stream Chemicals, $1 / 16$ " pellets (Linde 13X)), zeolite $Y$, sodium molecular sieve $4 \mathrm{~A}$ powder, and molecular sieve 3A powder were purchased from Alfa Aesar (Haverhill, MA, USA). Deion- 
ized water (DI) was obtained from Milli-Q ultrapure water purification system (Millipore, Billerica, MA, USA). A commercial PAN membrane, (MWCO 400,000, Ultura) which was used as a support layer for the electrospun nanofibers, was provided by Ultura (Oceanside, CA, USA).

\subsection{Fabrication of Mixed-Matrix Nanofibrous Membranes}

Zeolite 13X particles were grinded mechanically to obtain fine a powder. After grinding, particle size of $13 \mathrm{X}$ was measured using laser diffraction. The distribution of grinded particles was shown previously [7]. The particle size ranges from 0.6 to $6 \mu \mathrm{m}$. with an average diameter of $\sim 1.5 \mu \mathrm{m}$. An electrospinning process was used to fabricate PES nanofibers. Zeolite 13X and PES powders with a fixed weight ratio were dissolved in DMF under stirring at $70{ }^{\circ} \mathrm{C}$. Thereafter, a homogeneous casting solution was obtained after $24 \mathrm{~h}$ of stirring and mixing. The solution was then injected into a syringe pump.

Nanofibers were deposited onto the backside of the PAN membrane during the electrospinning process. Here the syringe pump flow rate was fixed at $0.5 \mathrm{~mL} \mathrm{~h}^{-1}$. The applied voltage was kept at $25 \mathrm{kV}$ and the distance between the needle tip and fiber collector was maintained at $25 \mathrm{~cm}$. These are the critical parameters to control the fiber diameter and the properties of the fibrous membranes formed. The $x \%$ PES $-y \%$ zeolite was used to denote the membranes with different compositions, where $x$ represents the wt $\%$ of PES to the polymer-solvent mixed casting solution, $y$ represents the $w t \%$ of $13 X$ with respect to PES in the solvent mixture.

\subsection{Characterization}

\section{Membrane Morphology}

The membrane surface and cross-section morphology were investigated by fieldemission scanning electron microscopy FESEM Model S-4800 (Hitachi Co., Tokyo, Japan) with $1 \mathrm{kV}$ electron beam. The membrane samples were dried in vacuum oven at $40^{\circ} \mathrm{C}$ at least $24 \mathrm{~h}$ to remove residue solvent and moisty before sample preparation. The membrane was then dipped in liquid nitrogen for a few seconds to obtain a uniform cross-section. Finally, the membrane was cut into pieces with appropriate size and subsequently mounted on the SEM sample holder by carbon conductive tabs (Ted Pella, Redding, CA, USA) for imaging.

\subsection{Performance of Mixed-Matrix Membranes}

Filtration experiments were performed using a stirred normal filtration cell (Sterlitech corporation, Kent, WA, USA) connected to a pressurized feed vessel from a nitrogen tank. During filtration, the feed solution was stirred to minimize concentration polarization. Prior to each test, the membrane coupons were compacted by filtering DI water until a steady permeate flux was obtained. The permeate flux was calculated based on the time-derivative of the permeate mass, which was measured by collecting the filtered water on a digital balance (Mettler Toledo, PL602-s) connected to a computer.

To evaluate membrane performance, 7 to $60 \mathrm{ppm}$ TAN feed solutions containing ammonium chloride $\left(\mathrm{NH}_{4} \mathrm{Cl}\right)$ were filtered through the compacted membranes using the dead-end filtration cell. Filtration pressure was adjusted for testing different membranes in order to control the permeate flux and subsequently the residence time for ammonium ion exchange. Multiple permeate samples were collected for each membrane to determine its ammonium removal capacity. TAN concentration in the sample was determined by the Phenol Hypochlorite Method [19] using a UV-VIS spectrophotometer (Thermo Scientific ${ }^{\mathrm{TM}}$ GENESYS 10S UV-Vis, Waltham, MA, USA). TAN removal rate was calculated by the concentration of TAN in the filtrate collected divided by the concentration of TAN in the feed using the following equation:

$$
\text { TAN removal } \%=\frac{C_{\text {permeate }}}{C_{\text {feed }}} \times 100
$$


where $C_{\text {filtrate }}$ and $C_{\text {feed }}$ represent the concentration of TAN in the permeate and feed solutions respectively. TAN removal capacity was determined by calculating the total amount of TAN removed over the course of filtration experiment divided by the amount of zeolite incorporated in the membrane in $\mathrm{mg} / \mathrm{g}$ using the following equation:

$$
\text { TAN Removal Capacity }=\frac{\sum C_{\text {permeate }} \times V_{\text {permeate }}}{W_{\text {zeolite }} 13 \mathrm{X}}
$$

\section{Results and Discussion}

\subsection{The Effects of Zeolite Loading on TAN Removal}

Our previous work [7] shows that ammonium uptake by zeolite 13X particles in the solution follows the Freundlich isotherm with a multilayer inhomogeneous adsorption mechanism. The adsorption capacity coefficient $\mathrm{K}_{\mathrm{F}}$ is about $17.6 \mathrm{mg} / \mathrm{g}$ zeolite. Moreover, the adsorption of ammonium ions in the solution is rather rapid reaching equilibrium with less than $30 \mathrm{~min}$. The adsorption kinetics follows the pseudo second order. The equilibrium $\mathrm{NH}_{4}{ }^{+}$adsorption capacity was calculated to be $28.5 \mathrm{mg}$ TAN per gram of zeolite. However, adsorption capacity is strongly dependent on the experimental condition including the ratio of zeolite to TAN.

To investigate the effects of zeolite $13 \mathrm{X}$ loading on ammonium removal, mixed-matrix membranes were fabricated incorporating zeolite 13X equivalent to 0,50 and $100 \mathrm{wt} \%$ with respect to PES amount in the casting solution. The filtration experiments were conducted using 45 millimeter $(\mathrm{mm})$ in diameter cut membrane coupons from the fabricated electrospun nanofiber membranes. Prior to ammonium exchange experiments, membranes were compacted using DI water until a stable flux was obtained. Since the mechanism for ammonium removal from the feed solution is via ion-exchange process, residence time of the feed solution with the membrane is an important parameter. Based on the DI water fluxes of the fabricated mixed-matrix membranes and our earlier studies [7], a flux of about $70 \mathrm{LMH}$ can ensure sufficient time for the ion-exchange process while maintaining the efficiency of the filtration process. More details on the effects of flux on ammonium removal will be discussed in the next section.

Here, a flux of $70 \mathrm{LMH}$ was maintained by adjusting the pressure for all three membranes with different zeolite 13X loadings. Figure 1 shows the percentage of TAN removed as a function of the filtrate volume collected for three membranes. All feed solutions contain $15 \mathrm{ppm}$ TAN. Permeate samples were analyzed for each $50 \mathrm{~mL}$ collected. The $20 \%$ PES-0\%Zeolite13X membrane without incorporating zeolite13X showed less than $20 \%$ TAN removal during the first $200 \mathrm{~mL}$ of filtrate collected. Thereafter, TAN removal quickly decreases to almost 0 for the remaining $300 \mathrm{~mL}$ of filtrate collected. This indicates that PES membranes possess some negatively charged sites and could perform limited ammonium ion-exchange with the feed solution. However, its TAN removal capacity is very limited. When $50 \mathrm{wt} \%$ of zeolite $13 \mathrm{X}$ was incorporated into the membrane (20\%PES- $50 \%$ Zeolite $13 \mathrm{X})$, the membrane showed over $97 \%$ TAN removal during the first $100 \mathrm{~mL}$ of filtrate. However, TAN removal rate quickly decreased during the next $200 \mathrm{~mL}$ of filtrate to just over $20 \%$. The TAN removal rate continued to decrease during the remaining $200 \mathrm{~mL}$ of filtrate. However, when $100 \mathrm{wt} \%$ of zeolite $13 \mathrm{X}$ was incorporated into the membrane (20\%PES$100 \%$ Zeolite13X), TAN removal rate consistently reached over $95 \%$ for the first $250 \mathrm{~mL}$ permeate collected. Thereafter, TAN removal rate decreased to about $93 \%$ at $300 \mathrm{~mL}$ filtrate and $\sim 52 \%$ at $500 \mathrm{~mL}$ reaching $\sim 12 \%$ at $800 \mathrm{~mL}$ filtrate. It can be seen that the amount of TAN removed is directly proportional to the amount of zeolite $13 \mathrm{X}$ incorporated into the membrane in agreement with our previous findings [7].

Figure 2 shows the SEM images of the cross-sectional surfaces (top panel) and membrane top surfaces (bottom panel) for one of the fabricated mixed-matrix membranes at $20 \%$ PES- $100 \%$ Zeolite $13 \mathrm{X}$ composition. The magnification increases from left to right for the images taken. The zeolite particles can be visibly seen. Fiber diameters have also been measured based on these images as shown in Figure 3. Electrospun nanofiber diameters varied from 200 to $900 \mathrm{~nm}$ with the highest percentage appeared between 400 and $500 \mathrm{~nm}$. 
The diameters were measured without taking zeolite particles into consideration since these particles range from 0.6 to $6 \mu \mathrm{m}$, with an average diameter of $1.5 \mu \mathrm{m}$.

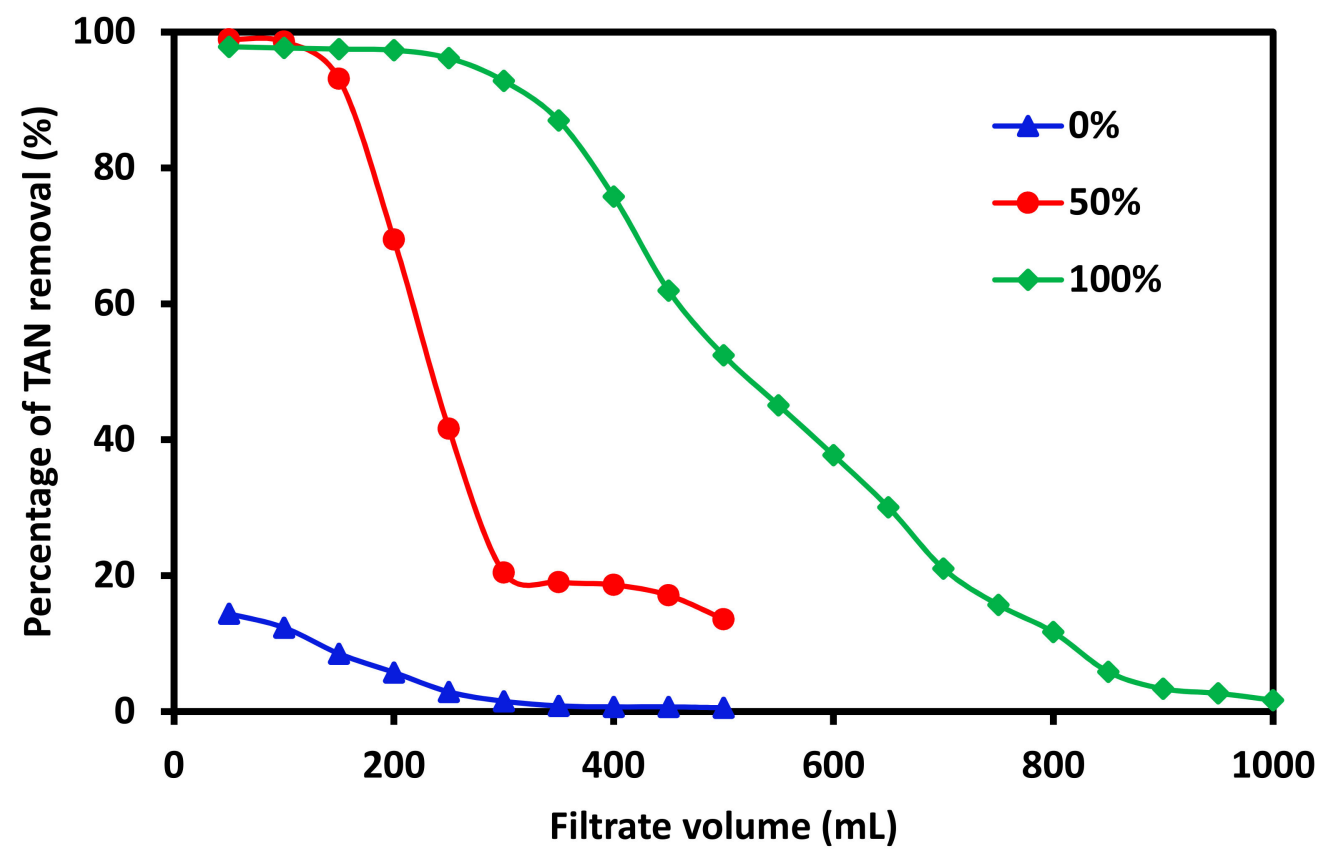

Figure 1. Percentage of TAN removed as a function of filtrate volume collected for three mixed matrix membranes incorporating 0,50 , and $100 \mathrm{wt} \%$ zeolite $13 \mathrm{X}$ with respect to PES polymer in the performance of membrane with various zeolite loadings.
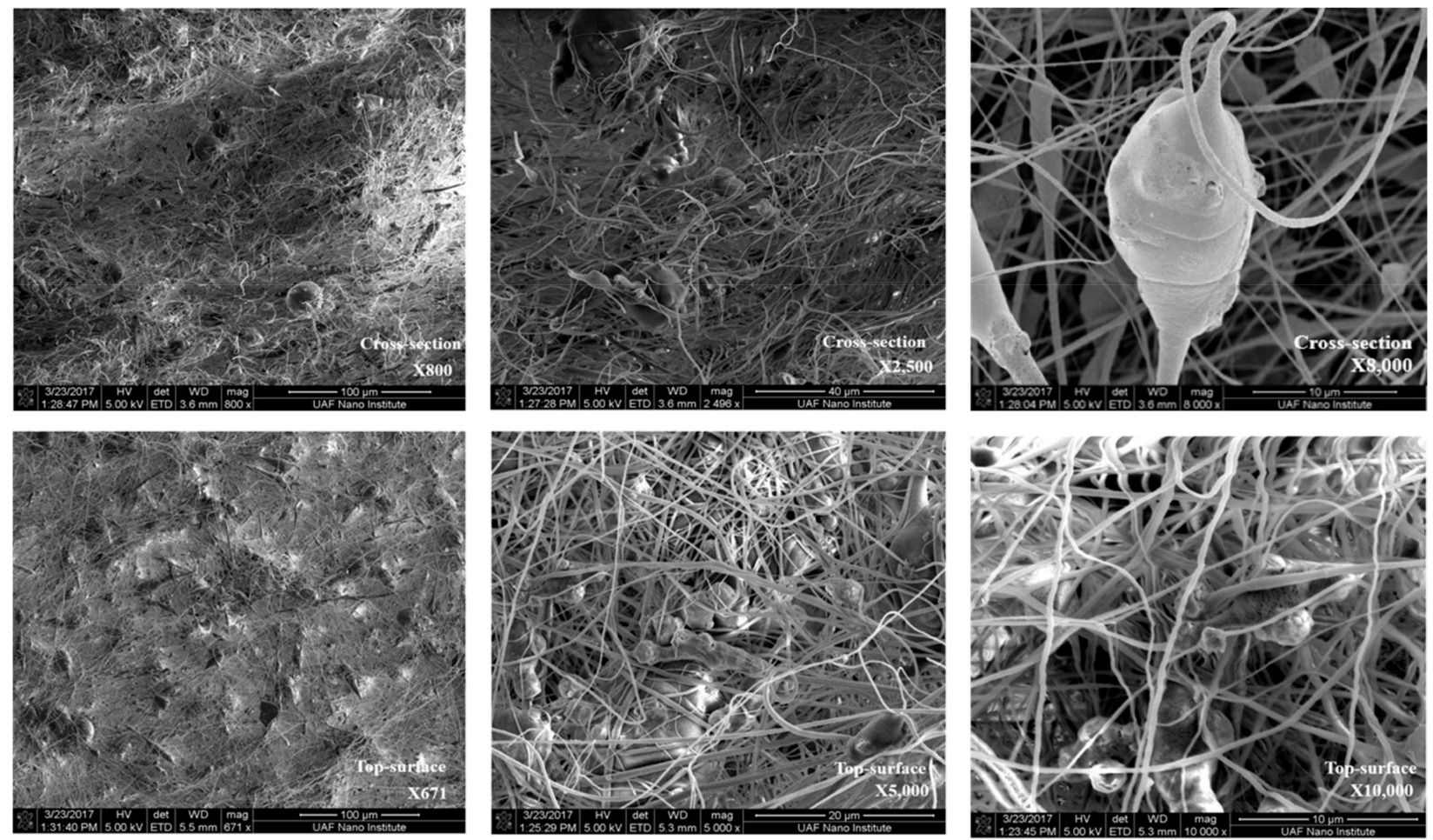

Figure 2. SEM images of cross-sectional surfaces (top panel) and top surfaces (bottom panel) of fabricated mixed matrix membrane (20\%PES-100\%Zeolite13X) with increased left to right magnifications. 


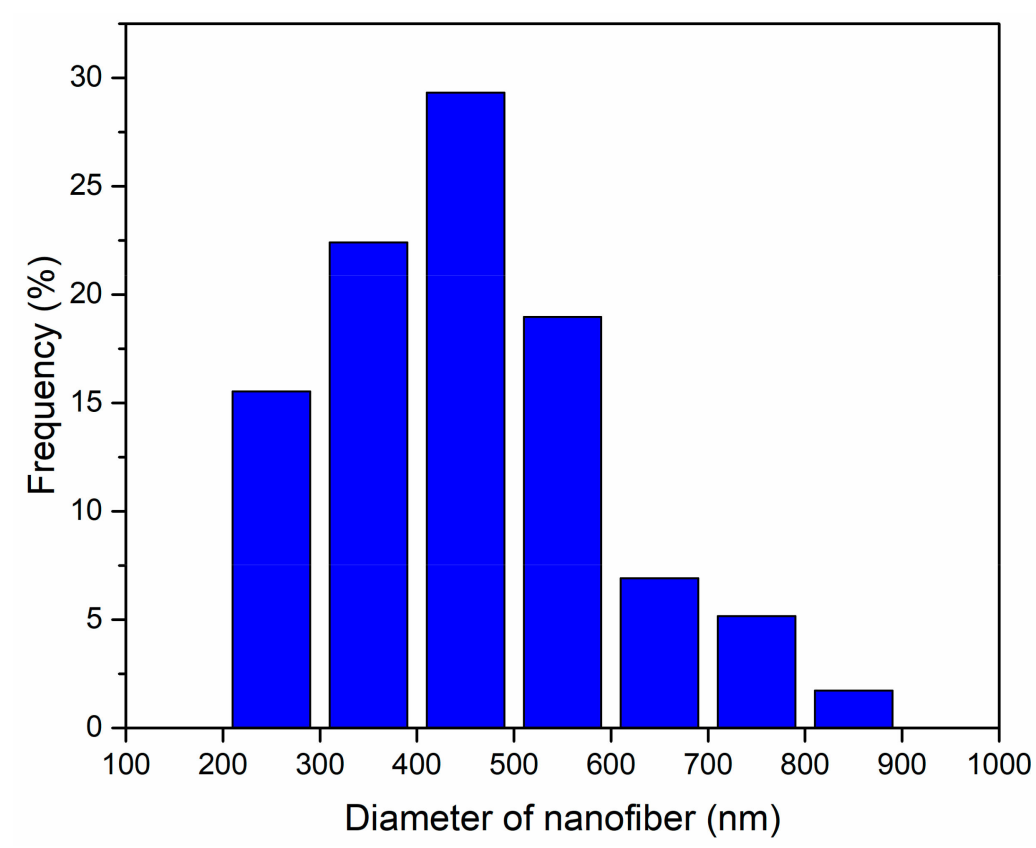

Figure 3. The nanofiber diameter distribution of electrospun $20 \%$ PES-100\%Zeolite13X membranes based on the images from SEM.

\subsection{The Effects of Filtration Flux on Ammonium Exchange and Removal}

Since the mechanism for ammonium ion removal from the wastewaters is ion-exchange, both the kinetics and thermodynamics of the ion-exchange process are important and need to be studied. Here, electrospun mixed-matrix membranes with the same composition of $20 \%$ PES- $100 \%$ Zeolite $13 \mathrm{X}$ were fabricated with approximately the same weight as shown in Table 1. These membranes were tested with 6 ppm TAN synthetic wastewaters at a flux of 70, 140, 210, and $280 \mathrm{LMH}$, respectively. The percentage of TAN removed in every $50 \mathrm{~mL}$ filtrate was measured and plotted as a function of the feed volume, as shown in Figure 4. Different flux values represent different kinetics for the ammonium ion exchange process. A total of $2000 \mathrm{~mL}$ feed volume was tested. It can be seen that for ammonium removal rate reached over $90 \%$ during the initial $650-850 \mathrm{~mL}$ of the feed depending on the flux. Thereafter, the flux declined rapidly over the next $1000 \mathrm{~mL}$ of the feed and eventually reduced to less than $10 \%$ at the last $50 \mathrm{~mL}$ of the filtrate collected. However, there are some differences between experiments with different fluxes. The total amount of TAN removed for each experiment was calculated and shown in Table 1. Since the actual membrane weight thereby its zeolite $13 \mathrm{X}$ content is slightly different, the total TAN amount removed does not necessarily reflect the effect of flux on the TAN removal capacity. The TAN removal capacity in mg over the total amount of zeolite 13X incorporated in the membrane in $\mathrm{g}$ was shown in the last column in Table 1. It can be seen that the lowest flux at $70 \mathrm{LMH}$ exhibited the highest TAN removal capacity reaching $53.7 \mathrm{mg} / \mathrm{g}$. The removal capacity reduced slightly to $\sim 52.2-52.4 \mathrm{mg} / \mathrm{g}$ for the 140 and $210 \mathrm{LMH}$ experiments. The TAN removal capacity reduced much more to $48.8 \mathrm{mg} / \mathrm{g}$ for filtration experiment at 280 LMH flux. For the remaining experiments, a filtration flux of $70 \mathrm{LMH}$ was kept. It is surprising to observe that the ammonium removal capacity for the electrospun membranes incorporating zeolite $13 \mathrm{X}$ is almost twice as high as the capacity of zeolite 13X particles without being incorporated. This is likely due to the aggregation of the naked particles when they were immersed in the solution. On the other hand, the zeolite particles in the membranes are dispersed and exposed to the feed containing the ammonium ions leading to the significant increase in the ammonium exchange capacity. 
Table 1. The TAN removal capacity as a function of filtration flux.

\begin{tabular}{|c|c|c|c|c|}
\hline Membrane Composition & $\begin{array}{l}\text { Membrane Weight } \\
(\mathrm{g})\end{array}$ & Flux (LMH) & $\begin{array}{l}\text { Total TAN Removed } \\
\text { (mg) }\end{array}$ & $\begin{array}{c}\text { TAN Removal } \\
\text { Capacity (mg/gzeolite) }\end{array}$ \\
\hline 20\%PES-100\%Zeolite13X & $1.18 \pm 0.06$ & 70 & $31.7 \pm 2.26$ & $53.7 \pm 3.83$ \\
\hline 20\%PES-100\%Zeolite13X & $1.18 \pm 0.09$ & 140 & $30.8 \pm 1.02$ & $52.2 \pm 1.73$ \\
\hline 20\%PES-100\%Zeolite13X & $1.10 \pm 0.09$ & 210 & $28.8 \pm 1.89$ & $52.4 \pm 3.44$ \\
\hline 20\%PES-100\%Zeolite13X & $1.05 \pm 0.10$ & 280 & $25.6 \pm 2.53$ & $48.8 \pm 4.87$ \\
\hline
\end{tabular}

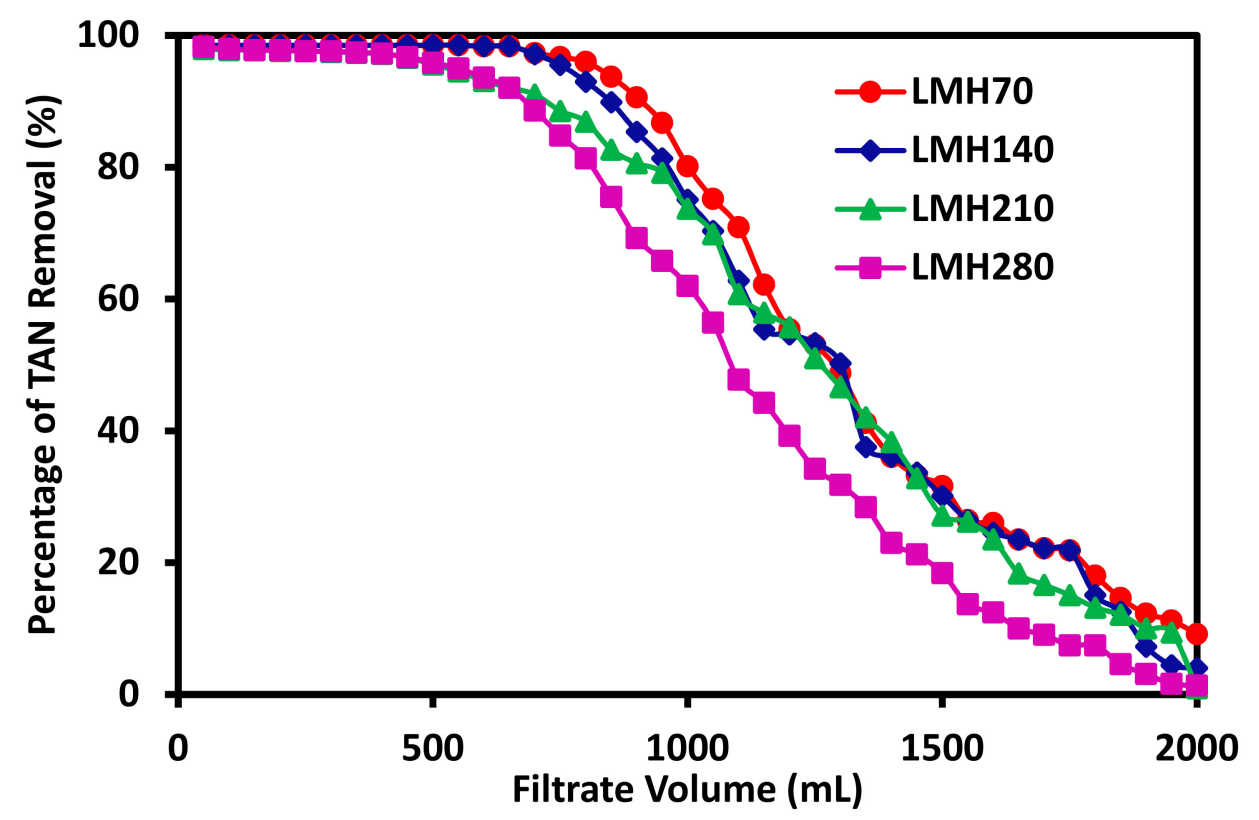

Figure 4. Variation of TAN removal rate with filtration flux with a $2000 \mathrm{~mL}$ feed containing $6 \mathrm{ppm}$ TAN for the fabricated membranes with the same composition but slightly different weight as shown in Table 1.

\subsection{The Effects of TAN Concentration on Its Removal Capacity}

The effects of feed concentration on the dynamic exchange capacity were also investigated. The feed solutions containing 7, 15, 30, and 60 ppm TAN concentrations were filtered through freshly fabricated membranes with 20\%PES-100\%Zeolite13X with similar weights. The TAN removal rate was plotted as a function of filtration feed volume passed through the membrane as shown in Figure 5. The flux was kept at 70 LMH based on previous studies. It can be seen that TAN removal rate reduced substantially as the TAN concentration in the feed multiplies. Table 2 lists the masses of the membranes fabricated, the corresponding feed concentrations, the total amount of TAN removed, and TAN removal capacity in mg of TAN per gram of zeolite 13X incorporated in the membrane. It can be seen that the dynamic exchange capacity does not change much when the TAN concentration increases. The ammonium ion exchange seems to be rather rapid and is not affected by the high amount of TAN present in the feed. This is consistent with the previous flux data that TAN removal is a rather rapid process and that only a slight decrease in the capacity was observed even at the highest filtration flux of $280 \mathrm{LMH}$. This also indicates the potential application of these MMMs for the removal of TAN at low concentration feed streams, such as aquaculture wastewaters, but also for other industrial processes producing high TAN feed streams. 


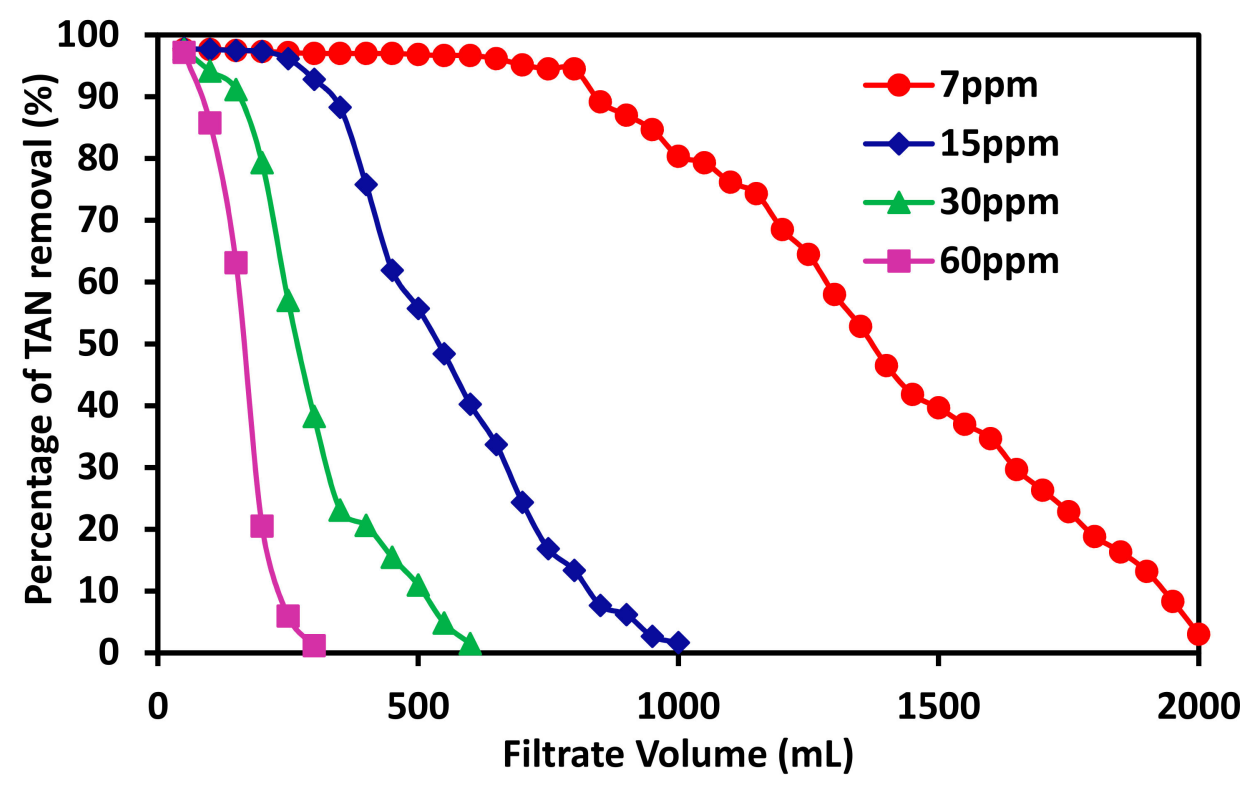

Figure 5. The effects of TAN concentration in the feed on its removal rate at LMH 70 for the fabricated membranes with the same composition.

Table 2. TAN removal capacities of fabricated mixed-matrix membranes with the composition of 20\%PES- $100 \%$ Zeolite $13 \mathrm{X}$ at feed concentrations of 7,15,30, and $60 \mathrm{ppm}$, respectively.

\begin{tabular}{lccccc}
\hline Membrane Composition & $\begin{array}{c}\text { Membrane } \\
\text { Weight (g) }\end{array}$ & $\begin{array}{c}\text { Flux } \\
\text { (LMH) }\end{array}$ & Feed Conc. (ppm) & $\begin{array}{c}\text { Total TAN } \\
\text { Removed (mg) }\end{array}$ & $\begin{array}{c}\text { TAN Removal } \\
\text { Capacity (mg/gzeolite) }\end{array}$ \\
\hline 20\%PES-100\%Zeolite13X & $1.15 \pm 0.09$ & 70 & 7 & $31.7 \pm 1.38$ & $55.1 \pm 2.38$ \\
\hline 20\%PES-100\%Zeolite13X & $1.16 \pm 0.07$ & 70 & 15 & $31.5 \pm 1.52$ & $54.4 \pm 2.62$ \\
\hline 20\%PES-100\%Zeolite13X & $1.20 \pm 0.13$ & 70 & 30 & $31.1 \pm 2.17$ & $51.8 \pm 3.62$ \\
\hline 20\%PES-100\%Zeolite13X & $1.17 \pm 0.11$ & 70 & 60 & $31.4 \pm 2.01$ & $53.7 \pm 3.44$ \\
\hline
\end{tabular}

\subsection{The Effects of Membrane Regeneration on Its Performance}

The previous studies on the effects of filtration flux and feed concentration on the TAN removal rate and TAN removal capacity for the fabricated mixed-matrix membranes used freshly made membranes with the same composition and approximately the same weight. The reuse and regeneration of the membranes were also investigated. Here, after the membrane was filtered with a $2000 \mathrm{~mL}$ feed solution containing 6 ppm TAN, the regeneration of the membranes was conducted by filtering the membrane using $2 \mathrm{M}$ $\mathrm{NaCl}$ solution at $70 \mathrm{LMH}$ until TAN in the filtrate cannot be detected. This process takes about $12 \mathrm{~h}$ and $2000 \mathrm{~mL}$ of the salt solution. Since $\mathrm{NH}_{4}{ }^{+}$ion and $\mathrm{Na}^{+}$have the same charge and are very similar to each other in terms of their ionic radii, it is expected that the exchange between the two ions are rather efficient. Indeed, it appears that after the first regeneration of the membrane, the TAN removal rate remains more or less the same as shown in Figure 6. The filtrate volumes with $90 \%$ TAN removal for both the virgin membrane and the regenerated membrane reached $850 \mathrm{~mL}$. However, there is some slightly loss of TAN removal capacity. During the subsequent 2 nd and 3rd regenerations, only $750 \mathrm{~mL}$ and $700 \mathrm{~mL}$, respectively, of the filtrates reached 90\% TAN removal rate. The loss of membrane capacity for TAN removal is more apparent as also can be seen clearly in Figure 6. This loss of capacity is likely due to the diffusion of the $\mathrm{NH}_{4}{ }^{+}$ions into the inner regions of the zeolite $13 \mathrm{X}$ particles leading to the unavailability of those sites for further adsorption of the ammonium ions. However, it can be seen from this study that these mixed-matrix membranes can be potentially used multiple times after regeneration using a $2 \mathrm{M} \mathrm{NaCl}$ salt solution. Moreover, if $\mathrm{NaNO}_{3}$ salt solution is used instead of $\mathrm{NaCl}$, 
$\mathrm{NH}_{4}{ }^{+}$can be recovered in the format of $\mathrm{NH}_{4} \mathrm{NO}_{3}$ solution, which can be directly used as a fertilizer. Not only these mixed-matrix membranes can be employed to remove TAN, but also $\mathrm{N}$ nutrient can be easily recovered by another ion-exchange process. Further studies are underway to investigate nutrient recovery.

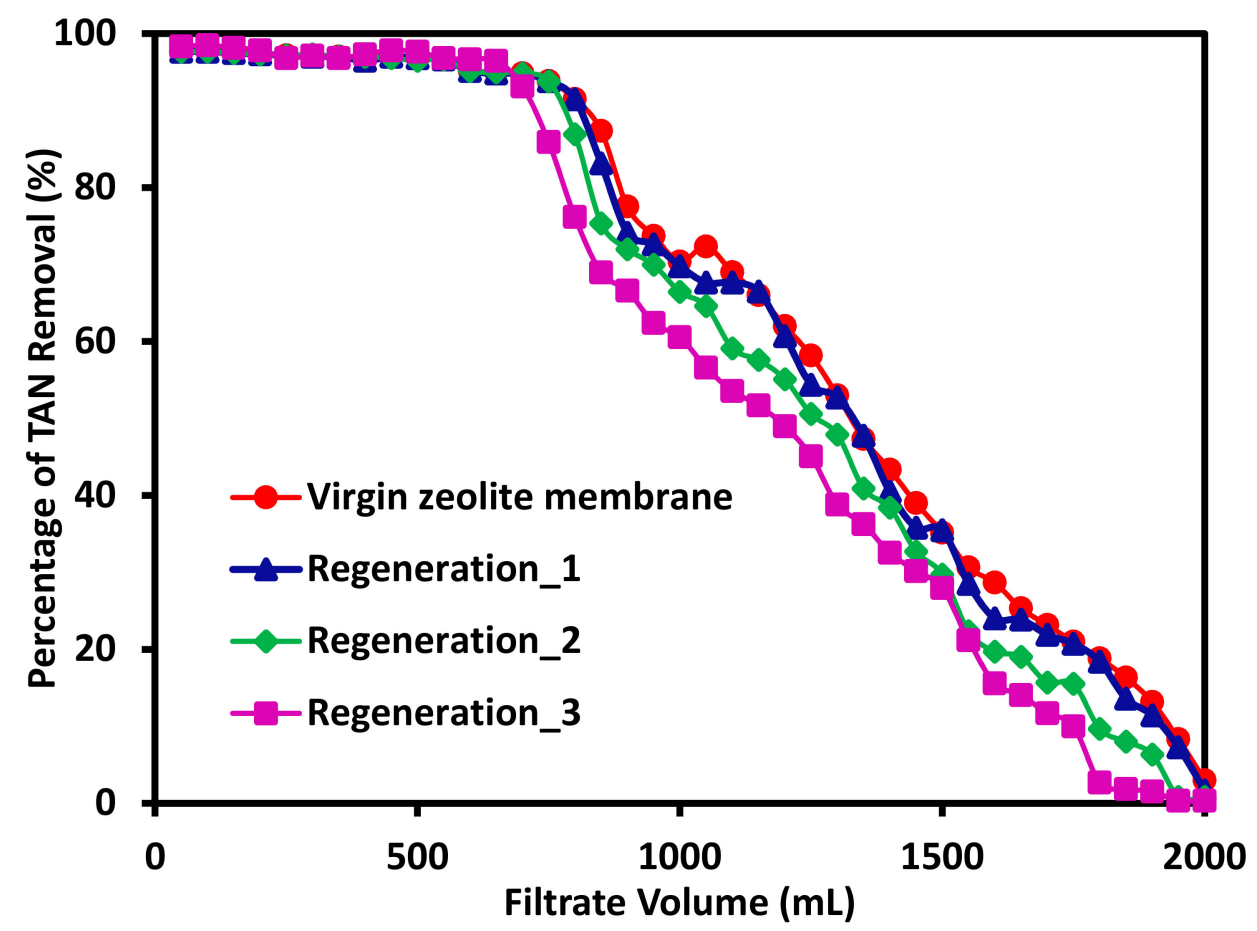

Figure 6. The TAN removal rates as a function of feed volume with the fabricated $20 \%$ PES100\%Zeolite13X mixed-matrix membranes over multiple removal and regeneration cycles.

\subsection{The Effects of Zeolite Type on the Performance of TAN Removal}

Mentioned previously, zeolite $13 \mathrm{X}$ is a rather inexpensive and abundant natural zeolite from volcanic ashes, it will not contribute much to the cost of fabricating these mixed-matrix membranes. On the other hand, there are many other zeolite types available including zeolite $3 \mathrm{~A}, 4 \mathrm{~A}$, and $\mathrm{Y}$. These zeolite particles possess specific properties such as high purity and with specific pore sizes. They also have a different $\mathrm{Al} / \mathrm{Si}$ ratio which is an important indicator for the ion-exchange capacity of the zeolites. Figure 7 shows the percentage of TAN removed as a function of the filtrate volume collected for the mixed-matrix membranes incorporating zeolite 13X, 3A, 4A, and Y. All the membranes contain $20 \% \mathrm{PES}$ and the same weight percentage of the zeolite particles. It can be seen that zeolite 13X demonstrates the highest TAN removal efficiency, followed by zeolite $4 \mathrm{~A}$, zeolite $3 \mathrm{~A}$ with zeolite $\mathrm{Y}$ possessing the lowest TAN removal efficiency.

Since these membranes incorporating different zeolite particle types have slightly different weights, the TAN removal capacity was calculated, as shown in Table 3. The weight of the membrane, the flux value for the filtration experiments, the permeate volume reached 90\% TAN removal and the total amount of TAN removed are also listed in Table 3. It can be seen that zeolite $13 X$ has the highest TAN removal capacity at $52.5 \mathrm{mg} / \mathrm{g}$. Zeolite $4 \mathrm{~A}$ has the second highest TAN removal capacity at $48.1 \mathrm{mg} / \mathrm{g}$. The other two zeolite materials $3 \mathrm{~A}$ and $\mathrm{Y}$ have substantially reduced capacity at 43.1 and $43.6 \mathrm{mg} / \mathrm{g}$, respectively. 


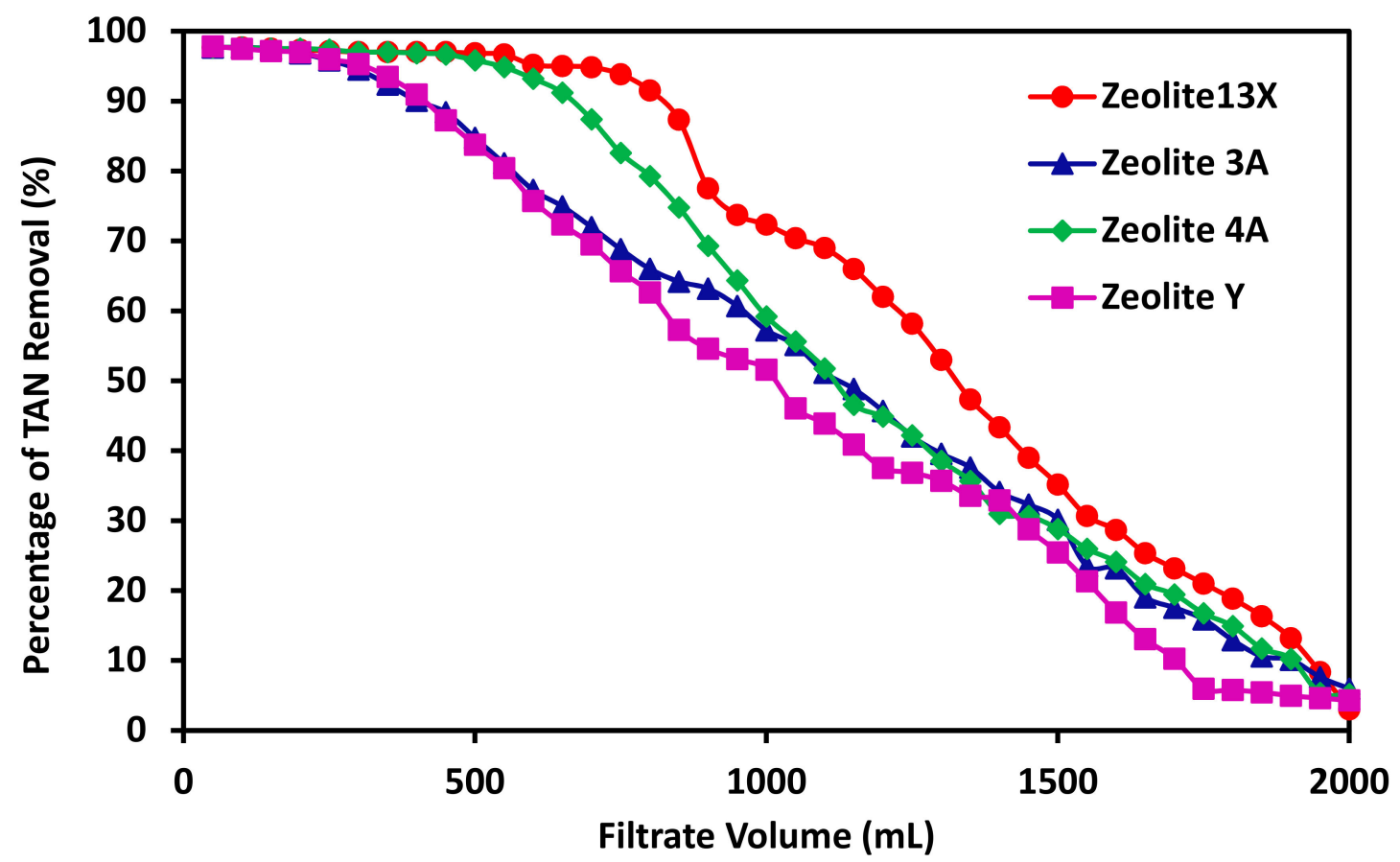

Figure 7. The percentage of TAN removal as a function of the filtrate collected for mixed matrix membranes incorporating different zeolite particles of 13X, 3A, 4A, and Y. The membranes have the same mass composition of 20\%PES-100\% Zeolite.

Table 3. TAN removal capacities for mixed-matrix membranes incorporating different zeolite types with the same mass composition and the feed concentration of $6 \mathrm{ppm}$. The weight of the membrane, and the filtrate volume with more than $90 \%$ TAN removal, the total amount of TAN removed are also shown.

\begin{tabular}{cccccc}
\hline Membrane Composition & $\begin{array}{c}\text { Membrane } \\
\text { Weight (g) }\end{array}$ & $\begin{array}{c}\text { Flux } \\
\text { (LMH) }\end{array}$ & $\begin{array}{c}\text { Permeate Volume } \\
\text { with } \mathbf{9 0 \%} \text { TAN } \\
\text { Removal (mL) }\end{array}$ & $\begin{array}{c}\text { Total TAN } \\
\text { Removed (mg) }\end{array}$ & $\begin{array}{c}\text { TAN Removal } \\
\text { Capacity } \\
\text { (mg/gzeolite) }\end{array}$ \\
\hline 20\%PES-100\%Zeolite 13X & $1.15 \pm 0.07$ & 70 & 800 & $30.2 \pm 0.75$ & $52.5 \pm 1.30$ \\
\hline 20\%PES-100\%Zeolite Y & $1.08 \pm 0.11$ & 70 & 400 & $23.6 \pm 1.87$ & $43.6 \pm 3.46$ \\
\hline 20\%PES-100\%Zeolite 3A & $1.12 \pm 0.09$ & 70 & 400 & $24.2 \pm 1.79$ & $43.1 \pm 3.19$ \\
\hline 20\%PES-100\%Zeolite 4A & $1.13 \pm 0.08$ & 70 & 650 & $27.2 \pm 1.59$ & $48.1 \pm 2.81$ \\
\hline
\end{tabular}

The differences between these different zeolite types can be due to several reasons. One of the major differences between these zeolite types is their ion-exchange capacity. Ion-exchange capacity is strongly dependent on the $\mathrm{Si} / \mathrm{Al}$ ratio for the zeolite material. The higher the $\mathrm{Si} / \mathrm{Al}$ ratio is, the lower the ion-exchange capacity will be. The higher $\mathrm{Al}$ content increases the negative charge density of the zeolite. For both zeolite 4A and 3A, the $\mathrm{Si} / \mathrm{Al}$ ratio is 1 . For zeolite $\mathrm{Y}$, the ratio is 2.46 . For zeolite $13 \mathrm{X}$ is 1.23 . Clearly zeolite $4 \mathrm{~A}$ and $3 \mathrm{~A}$ should have the highest ion-exchange capacity. However, pore size of the zeolite cages also plays an important role, zeolite 3A, 4A, and 13X have pore sizes of 3, 4, and $10 \AA$, respectively. Smaller pore size tends to limit the passage of the hydrated ions and their diffusion to the binding sites. As a result, zeolite $13 \mathrm{X}$ has the highest ammonium ion exchange capacity, zeolite $\mathrm{Y}$ and 3A have similarly low ammonium ion exchange capacity. Moreover, the filtrate volume with more than $90 \%$ TAN removal for each membrane is also shown in Table 3. The highest volume is zeolite $13 \mathrm{X}$ with $850 \mathrm{~mL}$, followed by zeolite $4 \mathrm{~A}$ at $650 \mathrm{~mL}$ with zeolite $3 \mathrm{~A}$ and $\mathrm{Y}$ at $400 \mathrm{~mL}$ consistent with the capacity values. In addition to the ammonium exchange capacity, cost of these zeolites is also a critical consideration of these mixed- matrix membrane with regard to applications for ammonium removal. Zeolite 4A, 3A, and Y are significantly more expensive than zeolite 13X. Mixed-matrix 
membranes incorporating zeolite $13 \mathrm{X}$ appear to be the best performing membranes for ammonium removal applications.

\subsection{Comparison with Other Zeolite Mixed-Matrix Membranes}

The performances of electrospun mixed-matrix membranes and previously fabricated membranes via phase inversion or pore filling on TAN removal are compared and listed in Table 4. The 13X pore-filled PES membrane (MWCO = $30 \mathrm{kDa}$, EMD Millipore) has the lowest TAN removal capacity at $10.4 \mathrm{mg} / \mathrm{g}_{\text {zeolite }}$. The phase inversion mixed-matrix membrane exhibits an intermediate TAN removal capacity at $19.8 \mathrm{mg} / \mathrm{g}_{\text {zeolite }}$. The electrospun membrane has the highest capacity of $55.1 \mathrm{mg} / \mathrm{g}_{\text {zeolite }}$. The low capacity for pore-filled membrane is clear since zeolite particles are aggregated together when filled in the pores of the PES ultrafiltration membrane as discussed previously. For the membrane fabricated via phase inversion, zeolite particles are more dispersed in the polymer matrix compared to pore-filled membrane leading to an increase in the ion exchange capacity. For the electrospun membrane, it is more porous compared to the corresponding phase inversion one leading to a significant increase in the ion-exchange capacity by almost 3 times. Besides a significantly higher capacity, the loading of zeolite in the electrospun mixed-matrix membrane is also much higher leading to its superior performance.

Table 4. TAN removal capacity comparison among three different mixed-matrix membranes.

\begin{tabular}{cc}
\hline Composite Membrane & $\begin{array}{c}\text { TAN Removal Capacity } \\
\left(\mathbf{m g} / \mathbf{g}_{\text {zeolite }}\right)\end{array}$ \\
\hline $\begin{array}{c}\text { Phase Inversion Mixed-Matrix Membrane } \\
(15 \% \text { PSU-50\% Zeolite 13x })\end{array}$ & 19.8 \\
\hline Pored-Filled & 10.4 \\
\hline $\begin{array}{c}\text { Electrospun Mixed-Matrix Membrane } \\
(20 \% \text { PES-100\% Zeolite 13x })\end{array}$ & 55.1 \\
\hline
\end{tabular}

* The volume of the wastewater treated is based on the water contains 7 ppm TAN only without any other competitive ions present.

Table 4 shows the capacity in terms of the amount of water can be treated per membrane area in $\mathrm{L} / \mathrm{m}^{2}$ if $90 \%$ of the TAN is removed in the filtrate assuming that the concentration of TAN in the wastewater is $7 \mathrm{ppm}$. It can be seen that phase inversion fabricated membrane has the lowest volume TAN removal capacity. This is due to the limited loading of zeolite $13 \mathrm{X}$ particles possible for the mixed-matrix membrane without compromising its mechanical integrity. The pore-filled membrane has a higher capacity due to the fact that more zeolite particles can be filled and incorporated into the membrane pores. The electrospun membrane has the highest volume capacity at $750 \mathrm{~L} / \mathrm{m}^{2}$. This is due to the fact that electrospun membrane is able to incorporate significantly more zeolite particles and that the membrane is more porous compared to the corresponding phase inversion membrane. Electrospun mixed-matrix membrane can treat over 21 times more wastewater than phase inversion counterpart.

\section{Conclusions}

Electrospun mixed-matrix membranes incorporating natural zeolite particles $13 \mathrm{X}$ were fabricated for the removal of ammonium ions from the wastewaters. These fabricated membranes demonstrate a high ion exchange capacity and high permeability. The capacity for removal of TAN reaches $55 \mathrm{mg} / \mathrm{g}_{\text {zeolite }}$ incorporated, over 2.5 times higher than the previously fabricated mixed-matrix membranes via phase inversion. The capacity is not affected by the flux in the range of 70 to $210 \mathrm{LMH}$ due to the rapid ion exchange process. However, when the flux increased to $280 \mathrm{LMH}$, a light decrease in exchange capacity was observed. In addition, the TAN removal capacity remains the same when the TAN concentration in the feed increases from 7 to $60 \mathrm{ppm}$. The fabricated electrospun membrane has a throughput of $750 \mathrm{~L} / \mathrm{m}^{2}$ to reduce the synthetic $7 \mathrm{ppm}$ TAN feed to less than $1 \mathrm{ppm}$. The 
membranes are stable and can be regenerated multiple times by filtering $2 \mathrm{M} \mathrm{NaCl}$ through the membrane. No leaching of zeolite particles has been observed. Compared to zeolite $\mathrm{Y}$, $4 \mathrm{~A}$, and $3 \mathrm{~A}$ particles, mixed-matrix electrospun membranes incorporating the naturally occurring inexpensive zeolite $13 \mathrm{X}$ exhibits the highest ammonium exchange capacity.

Author Contributions: Conceptualization, X.Q. and S.R.W.; methodology, X.Q.; software, S.-T.C.; validation, S.-T.C.; formal analysis, X.Q. and S.-T.C.; investigation, S.-T.C.; resources, X.Q. and S.R.W.; data curation, S.-T.C.; writing-original draft preparation, X.Q. and S.-T.C.; writing-review and editing, X.Q.; supervision, X.Q.; project administration, X.Q.; funding acquisition, X.Q. and S.R.W. All authors have read and agreed to the published version of the manuscript.

Funding: This research was funded by Arkansas Bait and Ornamental Fish Growers Association through the National Science Foundation Industry/University Cooperative Research Center for Membrane Science, Engineering and Technology, the National Science Foundation (IIP 1361809) and the University of Arkansas.

Institutional Review Board Statement: Not applicable.

Informed Consent Statement: Not applicable.

Data Availability Statement: Data available upon request.

Acknowledgments: Funding for this work was provided by Arkansas Bait and Ornamental Fish Growers Association through the National Science Foundation Industry/University Cooperative Research Center for Membrane Science, Engineering and Technology, the National Science Foundation (IIP 1361809) and the University of Arkansas.

Conflicts of Interest: The authors declare no conflict of interest.

\section{References}

1. Ciambelli, P.; Corbo, P.; Porcelli, C.; Rimoli, A. Ammonia removal from wastewater by natural zeolites. I. Ammonium ion exchange properties of an Italian phillipsite tuff. Zeolites 1985, 5, 184-187. [CrossRef]

2. Wang, Y.-F.; Lin, F.; Pang, W.-Q. Ammonium exchange in aqueous solution using Chinese natural clinoptilolite and modified zeolite. J. Hazard. Mater. 2007, 142, 160-164. [CrossRef] [PubMed]

3. Zheng, H.; Han, L.; Ma, H.; Zheng, Y.; Zhang, H.; Liu, D.; Liang, S. Adsorption characteristics of ammonium ion by zeolite 13X. J. Hazard. Mater. 2008, 158, 577-584. [CrossRef] [PubMed]

4. Huang, H.; Xiao, X.; Yan, B.; Yang, L. Ammonium removal from aqueous solutions by using natural Chinese (Chende) zeolite as adsorbent. J. Hazard. Mater. 2010, 175, 247-252. [CrossRef] [PubMed]

5. Lei, L.; Li, X.; Zhang, X. Ammonium removal from aqueous solutions using microwave-treated natural Chinese zeolite. Sep. Purif. Technol. 2008, 58, 359-366. [CrossRef]

6. Arslan, A.; Veli, S. Zeolite 13X for adsorption of ammonium ions from aqueous solutions and hen slaughterhouse wastewaters. J. Taiwan Inst. Chem. Eng. 2012, 43, 393-398. [CrossRef]

7. Ahmadiannamini, P.; Eswaranandam, S.; Wickramasinghe, R.; Qian, X. Mixed-matrix membranes for efficient ammonium removal from wastewaters. J. Membr. Sci. 2017, 526, 147-155. [CrossRef]

8. Zhu, X.; Cui, W.; Li, X.; Jin, Y. Electrospun Fibrous Mats with High Porosity as Potential Scaffolds for Skin Tissue Engineering. Biomacromolecules 2008, 9, 1795-1801. [CrossRef] [PubMed]

9. Xiong, J.; Huo, P.; Ko, F.K. Fabrication of ultrafine fibrous polytetrafluoroethylene porous membranes by electrospinning. J. Mater. Res. 2009, 24, 2755-2761. [CrossRef]

10. Greiner, A.; Wendorff, J.H. Electrospinning: A Fascinating Method for the Preparation of Ultrathin Fibers. Angew. Chem. Int. Ed. 2007, 46, 5670-5703. [CrossRef] [PubMed]

11. Ding, B.; Wang, M.; Wang, X.; Yu, J.; Sun, G. Electrospun nanomaterials for ultrasensitive sensors. Mater. Today 2010, 13 , 16-27. [CrossRef]

12. Pilehvar-Soltanahmadi, Y.; Akbarzadeh, A.; Moazzez-Lalaklo, N.; Zarghami, N. An update on clinical applications of electrospun nanofibers for skin bioengineering. Artif. Cells Nanomed. Biotechnol. 2016, 44, 1350-1364. [CrossRef] [PubMed]

13. Thavasi, V.; Singh, G.; Ramakrishna, S. Electrospun nanofibers in energy and environmental applications. Energy Environ. Sci. 2008, 1, 205-221. [CrossRef]

14. Mercante, L.A.; Scagion, V.P.; Migliorini, F.L.; Mattoso, L.H.; Correa, D.S. Electrospinning-based (bio)sensors for food and agricultural applications: A review. TrAC Trends Anal. Chem. 2017, 91, 91-103. [CrossRef]

15. Patel, A.C.; Li, S.; Wang, C.; Zhang, W.; Wei, Y. Electrospinning of Porous Silica Nanofibers Containing Silver Nanoparticles for Catalytic Applications. Chem. Mater. 2007, 19, 1231-1238. [CrossRef] 
16. Filimon, A.; Olaru, N.; Doroftei, F.; Coroaba, A.; Dunca, S. Processing of quaternized polysulfones solutions as tool in design of electrospun nanofibers: Microstructural characteristics and antimicrobial activity. J. Mol. Liq. 2021, 330, 115664. [CrossRef]

17. Gentile, P.; Chiono, V.; Carmagnola, I.; Hatton, P.V. An Overview of Poly(lactic-co-glycolic) Acid (PLGA)-Based Biomaterials for Bone Tissue Engineering. Int. J. Mol. Sci. 2014, 15, 3640-3659. [CrossRef] [PubMed]

18. Chen, S.-T.; Wickramasinghe, S.R.; Qian, X. Electrospun Weak Anion-Exchange Fibrous Membranes for Protein Purification. Membranes 2020, 10, 39. [CrossRef] [PubMed]

19. Weatherburn, M.W. Phenol-hypochlorite reaction for determination of ammonia. Anal. Chem. 1967, 39, 971-974. [CrossRef] 